\title{
A New Approach in the Study of Oscillation Criteria of Even-Order Neutral Differential Equations
}

\author{
Osama Moaaz $^{1,+(\mathbb{D})}$, Jan Awrejcewicz ${ }^{2, *,+} \mathbb{( D}$ and Omar Bazighifan ${ }^{3,+}(\mathbb{D}$ \\ 1 Department of Mathematics, Faculty of Science, Mansoura University, Mansoura 35516, Egypt; \\ o_moaaz@mans.edu.eg \\ 2 Department of Automation, Biomechanics and Mechatronics, Lodz University of Technology, \\ 1/15 Stefanowski St., 90-924 Lodz, Poland \\ 3 Department of Mathematics, Faculty of Science, Hadhramout University, Hadhramout 50512, Yemen; \\ o.bazighifan@gmail.com \\ * Correspondence: jan.awrejcewicz@p.lodz.pl \\ + These authors contributed equally to this work.
}

Received: 17 January 2020; Accepted: 31 January 2020; Published: 5 February 2020

\begin{abstract}
Based on the comparison with first-order delay equations, we establish a new oscillation criterion for a class of even-order neutral differential equations. Our new criterion improves a number of existing ones. An illustrative example is provided.
\end{abstract}

Keywords: even-order differential equations; neutral delay; oscillation

\section{Introduction}

In the last decade, many studies have been carried out on the oscillatory behavior of various types of functional differential equations, see [1-24] and the references cited therein. As a result of numerous applications in technology and natural science, the issue of oscillation of nonlinear neutral delay differential equation has caught the attention of many researchers, see $[1,3-5,8,12,17,19,22-24]$. For instance, they are frequently used for the study of distributed networks containing lossless transmission lines, see [11].

In this paper, we are concerned with improving the oscillation criteria for the even-order neutral differential equation of the form

$$
\left(r(t)\left(z^{(n-1)}(t)\right)^{\alpha}\right)^{\prime}+q(t) x^{\alpha}(\sigma(t))=0
$$

where $t \geq t_{0}, n \geq 4$ is an even natural number and $z(t):=x(t)+p(t) x(\tau(t))$. In this work, we assume that $\alpha$ is a quotient of odd positive integers, $r \in C\left[t_{0}, \infty\right), r(t)>0, r^{\prime}(t) \geq 0$, $\int_{t_{0}}^{\infty} r^{-1 / \alpha}(s) \mathrm{d} s=\infty, p, q \in C\left[t_{0}, \infty\right), q(t)>0,0 \leq p(t)<p_{0}<\infty, q(t)$ is not identically zero for large $t, \tau \in C^{1}\left[t_{0}, \infty\right), \sigma \in C\left[t_{0}, \infty\right), \tau^{\prime}(t)>0, \tau(t) \leq t$ and $\lim _{t \rightarrow \infty} \tau(t)=\lim _{t \rightarrow \infty} \sigma(t)=\infty$.

By a solution of (1) we mean a function $x \in C^{3}\left[t_{y}, \infty\right), t_{y} \geq t_{0}$, which has the property $r(t)\left(z^{(n-1)}(t)\right)^{\alpha} \in C^{1}\left[t_{y}, \infty\right)$, and satisfies (1) on $\left[t_{y}, \infty\right)$. We consider only those solutions $x$ of (1) which satisfy $\sup \{|x(t)|: t \geq T\}>0$, for all $T \geq t_{y}$. A solution $x$ of (1) is said to be non-oscillatory if it is positive or negative, ultimately; otherwise, it is said to be oscillatory.

A neutral delay differential equation is a differential equation in which the highest-order derivative of the unknown function appears both with and without delay.

In the following, we briefly review some important oscillation criteria obtained for higher-order neutral equations which can be seen as a motivation for this paper. 
In 1998, based on establishing comparison theorems that compare the $n$ th-order equation with only one first-order delay differential equations, Zafer [23] proved that the even-order differential equation

$$
z^{(n)}(t)+q(t) x(\sigma(t))=0
$$

is oscillatory if

$$
\liminf _{t \rightarrow \infty} \int_{\sigma(t)}^{t} Q(s) \mathrm{d} s>\frac{(n-1) 2^{(n-1)(n-2)}}{\mathrm{e}}
$$

or

$$
\limsup _{t \rightarrow \infty} \int_{\sigma(t)}^{t} Q(s) \mathrm{d} s>(n-1) 2^{(n-1)(n-2)}, \sigma^{\prime}(t) \geq 0 .
$$

where $Q(t):=\sigma^{n-1}(t)(1-p(\sigma(t))) q(t)$. In a similar approach, Zhang and Yan [24] proved that (2) is oscillatory if either

$$
\lim \inf _{t \rightarrow \infty} \int_{\sigma(t)}^{t} Q(s) \mathrm{d} s>\frac{(n-1) !}{\mathrm{e}}
$$

or

$$
\lim \sup _{t \rightarrow \infty} \int_{\sigma(t)}^{t} Q(s) \mathrm{d} s>(n-1) !, \sigma(t) \geq 0 .
$$

It's easy to note that $(n-1) !<(n-1) 2^{(n-1)(n-2)}$ for $n>3$, and hence results in [24] improved results of Zafer in [23].

For nonlinear equation, Xing et al. [22] proved that (1) is oscillatory if

$$
\left(\sigma^{-1}(t)\right)^{\prime} \geq \sigma_{0}>0, \tau^{\prime}(t) \geq \tau_{0}>0, \tau^{-1}(\sigma(t))<t
$$

and

$$
\lim \inf _{t \rightarrow \infty} \int_{\tau^{-1}(\sigma(t))}^{t} \frac{\widehat{q}(s)}{r(s)}\left(s^{n-1}\right)^{\alpha} \mathrm{d} s>\left(\frac{1}{\sigma_{0}}+\frac{p_{0}^{\alpha}}{\sigma_{0} \tau_{0}}\right) \frac{((n-1) !)^{\alpha}}{\mathrm{e}}
$$

where $\widehat{q}(t):=\min \left\{q\left(\sigma^{-1}(t)\right), q\left(\sigma^{-1}(\tau(t))\right)\right\}$.

If we apply the previous results to the equation

$$
\left(x(t)+\frac{7}{8} x\left(\frac{1}{\mathrm{e}} t\right)\right)^{(4)}+\frac{q_{0}}{t^{4}} x\left(\frac{1}{\mathrm{e}^{2}} t\right)=0, t \geq 1,
$$

then we get that (6) is oscillatory if

\begin{tabular}{|l|c|c|c|}
\hline The condition & $(3)$ & $(4)$ & $(5)$ \\
\hline The criterion & $q_{0}>113,981.3$ & $q_{0}>3561.9$ & $q_{0}>3008.5$ \\
\hline
\end{tabular}

Hence, Xing et al. [22] improved the results in [23,24].

By establishing a new comparison theorem that compare the higher-order Equation (1) with a couple of first-order delay differential equations, we improve the results in [22-24]. An example is presented to illustrate our main results.

In order to discuss our main results, we need the following lemmas:

Lemma 1 ([13]). If the function $x$ satisfies $x^{(i)}(t)>0, i=0,1, \ldots, n$, and $x^{(n+1)}(t)<0$, then

$$
\frac{x(t)}{t^{n} / n !} \geq \frac{x^{\prime}(t)}{t^{n-1} /(n-1) !} \text {. }
$$


Lemma 2 ([2] Lemma 2.2.3). Let $x \in C^{n}\left(\left[t_{0}, \infty\right),(0, \infty)\right)$. Assume that $x^{(n)}(t)$ is of fixed sign and not identically zero on $\left[t_{0}, \infty\right)$ and that there exists a $t_{1} \geq t_{0}$ such that $x^{(n-1)}(t) x^{(n)}(t) \leq 0$ for all $t \geq t_{1}$. If $\lim _{t \rightarrow \infty} x(t) \neq 0$, then for every $\mu \in(0,1)$ there exists $t_{\mu} \geq t_{1}$ such that

$$
x(t) \geq \frac{\mu}{(n-1) !} t^{n-1}\left|x^{(n-1)}(t)\right| \text { for } t \geq t_{\mu} .
$$

Lemma 3 ([3] Lemmas 1 and 2). Assume that $u, v \geq 0$ and $\beta$ is a positive real number. Then

$$
(u+v)^{\beta} \leq 2^{\beta-1}\left(u^{\beta}+v^{\beta}\right), \text { for } \beta \geq 1
$$

and

$$
(u+v)^{\beta} \leq u^{\beta}+v^{\beta}, \text { for } \beta \leq 1 .
$$

\section{Main Results}

Here, we define the next notation:

$$
\begin{gathered}
P_{k}(t)=\frac{1}{p\left(\tau^{-1}(t)\right)}\left(1-\frac{\left(\tau^{-1}\left(\tau^{-1}(t)\right)\right)^{k-1}}{\left(\tau^{-1}(t)\right)^{k-1} p\left(\tau^{-1}\left(\tau^{-1}(t)\right)\right)}\right), \text { for } k=2, n, \\
R_{0}(t)=\left(\frac{1}{r(t)} \int_{t}^{\infty} q(s) P_{2}^{\alpha}(\sigma(s)) \mathrm{d} s\right)^{1 / \alpha}
\end{gathered}
$$

and

$$
R_{m}(t)=\int_{t}^{\infty} R_{m-1}(s) \mathrm{d} s, m=1,2, \ldots, n-3 .
$$

Lemma 4 ([20] Lemma 1.2). Assume that $x$ is an eventually positive solution of (1). Then, there exist two possible cases:

$$
\begin{array}{ll}
\left(\mathbf{I}_{1}\right) & z(t)>0, z^{\prime}(t)>0, z^{\prime \prime}(t)>0, z^{(n-1)}(t)>0, z^{(n)}(t)<0, \\
\left(\mathbf{I}_{2}\right) & z(t)>0, z^{(j)}(t)>0, z^{(j+1)}(t)<0 \text { for all odd integer } \\
& j \in\{1,3, \ldots, n-3\}, z^{(n-1)}(t)>0, z^{(n)}(t)<0,
\end{array}
$$

for $t \geq t_{1}$, where $t_{1} \geq t_{0}$ is sufficiently large.

Theorem 1. Let

$$
\frac{\left(\tau^{-1}\left(\tau^{-1}(t)\right)\right)^{n-1}}{\left(\tau^{-1}(t)\right)^{n-1} p\left(\tau^{-1}\left(\tau^{-1}(t)\right)\right)} \leq 1
$$

Assume that there exist positive functions $\eta, \zeta \in C^{1}\left(\left[t_{0}, \infty\right), \mathbb{R}\right)$ satisfying

$$
\eta(t) \leq \sigma(t), \eta(t)<\tau(t), \zeta(t) \leq \sigma(t), \zeta(t)<\tau(t), \zeta^{\prime}(t) \geq 0 \text { and } \lim _{t \rightarrow \infty} \eta(t)=\lim _{t \rightarrow \infty} \zeta(t)=\infty .
$$

If there exists a $\mu \in(0,1)$ such that the differential equations

$$
\psi^{\prime}(t)+\left(\frac{\mu\left(\tau^{-1}(\eta(t))\right)^{n-1}}{(n-1) ! r^{1 / \alpha}\left(\tau^{-1}(\eta(t))\right)}\right)^{\alpha} q(t) P_{n}^{\alpha}(\sigma(t)) \psi\left(\tau^{-1}(\eta(t))\right)=0
$$

and

$$
\phi^{\prime}(t)+\tau^{-1}(\zeta(t)) R_{n-3}(t) \phi\left(\tau^{-1}(\zeta(t))\right)=0
$$

are oscillatory, then Equation (1) is oscillatory.

Proof. Let $x$ be a non-oscillatory solution of (1) on $\left[t_{0}, \infty\right)$. Without loss of generality, we can assume that $x$ is eventually positive. It follows from Lemma 4 that there exist two possible cases $\left(\mathbf{I}_{1}\right)$ and $\left(\mathbf{I}_{2}\right)$. 
Assume that Case $\left(\mathbf{I}_{1}\right)$ holds. From the definition of $z(t)$, we see that

$$
x(t)=\frac{1}{p\left(\tau^{-1}(t)\right)}\left(z\left(\tau^{-1}(t)\right)-x\left(\tau^{-1}(t)\right)\right) .
$$

By repeating the same process, we find that

$$
\begin{aligned}
x(t) & =\frac{z\left(\tau^{-1}(t)\right)}{p\left(\tau^{-1}(t)\right)}-\frac{1}{p\left(\tau^{-1}(t)\right)}\left(\frac{z\left(\tau^{-1}\left(\tau^{-1}(t)\right)\right)}{p\left(\tau^{-1}\left(\tau^{-1}(t)\right)\right)}-\frac{x\left(\tau^{-1}\left(\tau^{-1}(t)\right)\right)}{p\left(\tau^{-1}\left(\tau^{-1}(t)\right)\right)}\right) \\
& \geq \frac{z\left(\tau^{-1}(t)\right)}{p\left(\tau^{-1}(t)\right)}-\frac{1}{p\left(\tau^{-1}(t)\right)} \frac{z\left(\tau^{-1}\left(\tau^{-1}(t)\right)\right)}{p\left(\tau^{-1}\left(\tau^{-1}(t)\right)\right)} .
\end{aligned}
$$

Using Lemma 1 , we get $z(t) \geq \frac{1}{(n-1)} t z^{\prime}(t)$ and hence the function $t^{1-n} z(t)$ is nonincreasing, which with the fact that $\tau(t) \leq t$ gives

$$
\left(\tau^{-1}(t)\right)^{n-1} z\left(\tau^{-1}\left(\tau^{-1}(t)\right)\right) \leq\left(\tau^{-1}\left(\tau^{-1}(t)\right)\right)^{n-1} z\left(\tau^{-1}(t)\right)
$$

Combining Equations (11) and (12), we conclude that

$$
\begin{aligned}
x(t) & \geq \frac{1}{p\left(\tau^{-1}(t)\right)}\left(1-\frac{\left(\tau^{-1}\left(\tau^{-1}(t)\right)\right)^{n-1}}{\left(\tau^{-1}(t)\right)^{n-1} p\left(\tau^{-1}\left(\tau^{-1}(t)\right)\right)}\right) z\left(\tau^{-1}(t)\right) \\
& =P_{n}(t) z\left(\tau^{-1}(t)\right) .
\end{aligned}
$$

From Equations (1) and (13), we obtain

$$
\left(r(t)\left(z^{(n-1)}(t)\right)^{\alpha}\right)^{\prime}+q(t) P_{n}^{\alpha}(\sigma(t)) z^{\alpha}\left(\tau^{-1}(\sigma(t))\right) \leq 0 .
$$

Since $\eta(t) \leq \sigma(t)$ and $z^{\prime}(t)>0$, we get

$$
\left(r(t)\left(z^{(n-1)}(t)\right)^{\alpha}\right)^{\prime} \leq-q(t) P_{n}^{\alpha}(\sigma(t)) z^{\alpha}\left(\tau^{-1}(\eta(t))\right)
$$

Now, by using Lemma 2, we have

$$
z(t) \geq \frac{\mu}{(n-1) !} t^{n-1} z^{(n-1)}(t) .
$$

for some $\mu \in(0,1)$. It follows from (14) and (15) that, for all $\mu \in(0,1)$,

$$
\left(r(t)\left(z^{(n-1)}(t)\right)^{\alpha}\right)^{\prime}+\left(\frac{\mu\left(\tau^{-1}(\eta(t))\right)^{n-1}}{(n-1) !}\right)^{\alpha} q(t) P_{n}^{\alpha}(\sigma(t))\left(z^{(n-1)}\left(\tau^{-1}(\eta(t))\right)\right)^{\alpha} \leq 0 .
$$

Thus, if we set $\psi(t)=r(t)\left(z^{(n-1)}(t)\right)^{\alpha}$, then we see that $\psi$ is a positive solution of the first-order delay differential inequality

$$
\psi^{\prime}(t)+\left(\frac{\mu\left(\tau^{-1}(\eta(t))\right)^{n-1}}{(n-1) ! r^{1 / \alpha}\left(\tau^{-1}(\eta(t))\right)}\right)^{\alpha} q(t) P_{n}^{\alpha}(\sigma(t)) \psi\left(\tau^{-1}(\eta(t))\right) \leq 0
$$

It is well known (see [21] (Theorem 1)) that the corresponding Equation (9) also has a positive solution, which is a contradiction. 
Assume that Case $\left(\mathbf{I}_{2}\right)$ holds. Using Lemma 1, we get that

$$
z(t) \geq t z^{\prime}(t)
$$

and thus the function $t^{-1} z(t)$ is nonincreasing, eventually. Since $\tau^{-1}(t) \leq \tau^{-1}\left(\tau^{-1}(t)\right)$, we obtain

$$
\tau^{-1}(t) z\left(\tau^{-1}\left(\tau^{-1}(t)\right)\right) \leq \tau^{-1}\left(\tau^{-1}(t)\right) z\left(\tau^{-1}(t)\right)
$$

Combining (11) and (17), we find

$$
\begin{aligned}
x(t) & \geq \frac{1}{p\left(\tau^{-1}(t)\right)}\left(1-\frac{\left(\tau^{-1}\left(\tau^{-1}(t)\right)\right)}{\left(\tau^{-1}(t)\right) p\left(\tau^{-1}\left(\tau^{-1}(t)\right)\right)}\right) z\left(\tau^{-1}(t)\right) \\
& =P_{2}(t) z\left(\tau^{-1}(t)\right)
\end{aligned}
$$

which with (1) yields

$$
\left(r(t)\left(z^{(n-1)}(t)\right)^{\alpha}\right)^{\prime}+q(t) P_{2}^{\alpha}(\sigma(t)) z^{\alpha}\left(\tau^{-1}(\sigma(t))\right) \leq 0
$$

Since $\zeta(t) \leq \sigma(t)$ and $z^{\prime}(t)>0$, we have that

$$
\left(r(t)\left(z^{(n-1)}(t)\right)^{\alpha}\right)^{\prime} \leq-q(t) P_{2}^{\alpha}(\sigma(t)) z^{\alpha}\left(\tau^{-1}(\zeta(t))\right)
$$

Integrating the (18) from $t$ to $\infty$, we obtain

$$
z^{(n-1)}(t) \geq R_{0}(t) z\left(\tau^{-1}(\zeta(t))\right)
$$

Integrating this inequality from $t$ to $\infty$ a total of $n-3$ times, we obtain

$$
z^{\prime \prime}(t)+R_{n-3}(t) z\left(\tau^{-1}(\zeta(t))\right) \leq 0
$$

Thus, if we set $\phi(t):=z^{\prime}(t)$ and using (16), then we conclude that $\phi$ is a positive solution of

$$
\phi^{\prime}(t)+\tau^{-1}(\zeta(t)) R_{n-3}(t) \phi\left(\tau^{-1}(\zeta(t))\right) \leq 0 .
$$

It is well known (see [21] (Theorem 1)) that the corresponding Equation (10) also has a positive solution, which is a contradiction. The proof is complete.

Corollary 1. Assume that (7) holds and there exist positive functions $\eta, \zeta$ such that (8) holds. If

$$
\liminf _{t \rightarrow \infty} \int_{\tau^{-1}(\eta(t))}^{t}\left(\frac{\left(\tau^{-1}(\eta(s))\right)^{n-1}}{r^{1 / \alpha}\left(\tau^{-1}(\eta(s))\right)}\right)^{\alpha} q(s) P_{n}^{\alpha}(\sigma(s)) \mathrm{d} s>\frac{((n-1) !)^{\alpha}}{\mathrm{e}}
$$

and

$$
\liminf _{t \rightarrow \infty} \int_{\tau^{-1}(\zeta(t))}^{t} \tau^{-1}(\zeta(s)) R_{n-3}(s) \mathrm{d} s>\frac{1}{\mathrm{e}^{\prime}}
$$

then (1) is oscillatory.

Proof. It is well-known (see, e.g., [14] (Theorem 2)) that Condition (21) and (22) imply oscillation of (9) and (10), respectively. 
Example 1. Consider the equation

$$
\left(x(t)+p_{0} x(\delta t)\right)^{(n)}+\frac{q_{0}}{t^{n}} x(\lambda t)=0,
$$

where $t \geq 1, q_{0}>0, \delta \in\left(p_{0}^{-1 /(n-1)}, 1\right)$ and $\lambda \in(0, \delta)$. We note that $r(t)=1, p(t)=p_{0}, \tau(t)=$ $\delta t, \sigma(t)=\lambda t$ and $q(t)=q_{0} / t^{n}$. Thus, if we choose $\eta(t)=\zeta(t)=\lambda t$, then it's easy to see that (7) and (8) are satisfied. Moreover, we have

$$
\begin{aligned}
P_{k}(t) & =\frac{1}{p_{0}}\left(1-\frac{\delta^{1-k}}{p_{0}}\right), \text { for } k=2, n, \\
R_{0}(t) & =\frac{q_{0}}{p_{0}}\left(1-\frac{1}{\delta p_{0}}\right) \frac{t^{1-n}}{(n-1)},
\end{aligned}
$$

and

$$
R_{n-3}(t)=\frac{1}{(n-3) !} \frac{q_{0}}{p_{0}}\left(1-\frac{1}{\delta p_{0}}\right) \frac{1}{(n-2)(n-1) t^{2}} .
$$

Hence, Condition (21) and (22) become

$$
q_{0} \frac{1}{p_{0}}\left(\frac{\lambda}{\delta}\right)^{n-1}\left(1-\frac{\delta^{1-n}}{p_{0}}\right) \ln \frac{\delta}{\lambda}>\frac{(n-1) !}{\mathrm{e}}
$$

and

$$
q_{0} \frac{1}{p_{0}} \frac{\lambda}{\delta}\left(1-\frac{1}{\delta p_{0}}\right) \ln \frac{\delta}{\lambda}>\frac{(n-1) !}{\mathrm{e}},
$$

respectively. It's easy to see that (24) implies (25).

Therefore, by Corollary 1, we conclude that (23) is oscillatory if (24) holds.

Remark 1. For Equation (23), in particular case that $n=4, p_{0}=16, \delta=1 / 2$ and $\lambda=1 / 3$, Condition (24) yields $q_{0}>587.93$. Whereas, the criterion obtained from the results of [22] is $q_{0}>4850.4$. Hence, our results improve the results in [22].

\section{Conclusions}

In this paper, our method is based on presenting a new comparison theorem that compare the higher-order Equation (1) with a couple of first-order equations. There are numerous results concerning the oscillation criteria of first order Equations (9) and (10) (see, e.g., [14,25-27]), which include various forms of criteria as Hille/Nehari, Philos, etc. This allows us to obtain also various criteria for the oscillation of (1). Further, we can try to obtain oscillation criteria of (1) if $z(t):=x(t)-p(t) x(\tau(t))$ in the future work.

Author Contributions: The authors claim to have contributed equally and significantly in this paper. All authors read and approved the final manuscript.

Funding: The authors received no direct funding for this work.

Acknowledgments: The authors thank the reviewers for for their useful comments, which led to the improvement of the content of the paper.

Conflicts of Interest: There are no competing interests between the authors.

\section{References}

1. Agarwal, R.P.; Bohner, M.; Li, T.; Zhang, C. A new approach in the study of oscillatory behavior of even-order neutral delay diferential equations. Appl. Math. Comput. 2013, 225, 787-794.

2. Agarwal, R.; Grace, S.; O'Regan, D. Oscillation Theory for Difference and Functional Differential Equations; Kluwer Academic Publishers: Dordrecht, The Netherlands, 2000. 
3. Baculikova, B.; Dzurina, J. Oscillation theorems for second-order nonlinear neutral differential equations. Comput. Math. Appl. 2011, 62, 4472-4478. [CrossRef]

4. Baculikova, B.; Dzurina, J.; Li, T. Oscillation results for even-order quasi linear neutral functional differential equations. Electron. J. Differ. Equ. 2011, 2011, 1-9.

5. Baculikova, B.; Dzurina, J. Oscillation theorems for higher order neutral diferential equations. Appl. Math. Comput. 2012, 219, 3769-3778.

6. Bazighifan, O.; Cesarano, C. Some New Oscillation Criteria for Second-Order Neutral Differential Equations with Delayed Arguments. Mathematics 2019, 7, 619. [CrossRef]

7. Bazighifan, O.; Elabbasy, E.M.; Moaaz, O. Oscillation of higher-order differential equations with distributed delay. J. Inequal. Appl. 2019, 55, 1-9. [CrossRef]

8. Chatzarakis, G.E.; Elabbasy, E.M.; Bazighifan, O. An oscillation criterion in 4th-order neutral differential equations with a continuously distributed delay. Adv. Differ. Equ. 2019, 336, 1-9.

9. Elabbasy, E.M.; Cesarano, C.; Bazighifan, O.; Moaaz, O. Asymptotic and oscillatory behavior of solutions of a class of higher order differential equation. Symmetry 2019, 11, 1434. [CrossRef]

10. Elabbasy, E.M.; Hassan, T.S.; Moaaz, O. Oscillation behavior of second-order nonlinear neutral differential equations with deviating arguments. Opusc. Math. 2012, 32, 719-730. [CrossRef]

11. Hale, J.K. Theory of Functional Differential Equations; Springer: New York, NY, USA, 1977.

12. Li, T.; Han, Z.; Zhao, P.; Sun, S. Oscillation of even-order neutral delay differential equations. Adv. Differ. Equ. 2010, 2010, 1-9. [CrossRef]

13. Kiguradze, I.T.; Chanturiya, T.A. Asymptotic Properties of Solutions of Nonautonomous Ordinary Differential Equations; Kluwer Academic Publishers: Dordrecht, The Netherlands, 1993.

14. Kitamura, Y.; Kusano, T. Oscillation of first-order nonlinear differential equations with deviating arguments. Proc. Am. Math. Soc. 1980, 78, 64-68. [CrossRef]

15. Moaaz, O. New criteria for oscillation of nonlinear neutral differential equations. Adv. Differ. Equ. 2019, 2019, 484. [CrossRef]

16. Moaaz, O.; Elabbasy, E.M.; Bazighifan, O. On the asymptotic behavior of fourth-order functional differential equations. Adv. Differ. Equ. 2017, 2017, 261. [CrossRef]

17. Moaaz, O.; Elabbasy, E.M.; Muhib, A. Oscillation criteria for even-order neutral differential equations with distributed deviating arguments. Adv. Differ. Equ. 2019, 297, 1-10. [CrossRef]

18. Moaaz, O.; Elabbasy, E.M.; Shaaban, E. Oscillation criteria for a class of third order damped differential equations. Arab. J. Math. Sci. 2018, 24, 16-30. [CrossRef]

19. Parhi, N.; Tripathy, A. On oscillatory fourth order linear neutral differential equations-I. Math. Slovaca 2004, 54, 389-410.

20. Philos, C.G. A new criterion for the oscillatory and asymptotic behavior of delay differential equations. Bull. Acad. Pol. Sci. Sér. Sci. Math. 1981, 39, 61-64.

21. Philos, C.G. On the existence of non-oscillatory solutions tending to zero at $\infty$ for differential equations with positive delays. Arch. Math. 1981, 36, 168-178. [CrossRef]

22. Xing, G.; Li, T.; Zhang, C. Oscillation of higher-order quasi linear neutral differential equations. Adv. Differ. Equ. 2011, 2011, 45. [CrossRef]

23. Zafer, A. Oscillation criteria for even order neutral differential equations. Appl. Math. Lett. 1998, 11, $21-25$. [CrossRef]

24. Zhang, Q.; Yan, J. Oscillation behavior of even order neutral differential equations with variable coefficients. Appl. Math. Lett. 2006, 19, 1202-1206. [CrossRef]

25. Ladas, G.; Lakshmikantham, V.; Papadakis, L.S. Oscillations of Higher-Order Retarded Differential Equations Generated by the Retarded Arguments, Delay and Functional Differential Equations and Their Applications; Academic Press: New York, NY, USA, 1972; pp. 219-231. 
26. Koplatadze, R.G.; Chanturija, T.A. Oscillating and monotone solutions of first-order differential equations with deviating argument. Differ. Uravn. 1982, 18, 1463-1465.

27. Braverman, E.; Karpuz, B. On oscillation of differential and difference equations with non-monotone delays. Appl. Math. Comput. 2011, 218, 3880-3887. [CrossRef]

(C) 2020 by the authors. Licensee MDPI, Basel, Switzerland. This article is an open access article distributed under the terms and conditions of the Creative Commons Attribution (CC BY) license (http:/ / creativecommons.org/licenses/by/4.0/). 